\title{
Modelado mecanobiológico de la formación de placa de ateroma en arteria carótida de paciente específico
}

\author{
Patricia Hernández López, Myriam Cilla Hernández, Miguel Ángel Martínez Barca, \\ Estefanía Peña Baquedano \\ Applied Mechanics and Bioengineering (AMB) \\ Instituto de Investigación en Ingeniería de Aragón (I3A) \\ Universidad de Zaragoza, Mariano Esquillor s/n, 50018, Zaragoza, Spain. \\ Tel. +34-976762707, e-mail: phernand@unizar.es
}

\section{Resumen}

Con este proyecto se pretende desarrollar un modelo computacional capaz de reproducir el proceso de formación de placa de ateroma en arterias. Para ello, se tienen en cuenta multitud de poblaciones celulares que intervienen en el proceso, y se emplean geometrías correspondiendes a bifurcaciones de carótidas de paciente específico.

\section{Métodos}

Se ha implementado un modelo matemático desarrollado previamente [1] en geometrías de paciente específico, considerando la tensión tangencial entre el flujo sanguíneo y la pared arterial (WSS) como principal estímulo mecánico para la aparición de la placa de ateroma. Esto se ha realizado ya que se ha determinado por varios autores que las zonas de lesión endotelial (en las cuales se produce un aumento de la permeabilidad del endotelio y, por tanto, flujo de sustancias como el LDL del torrente sanguíneo a la pared arterial) son las zonas susceptibles de aparición de placa de ateroma.

Las especies químicas consideradas en el modelo computacional son: LDL, LDL oxidado, monocitos, macrófagos, citoquinas, células musculares contráctiles y sintéticas, células espumosas y fibras de colágeno. Dicho modelo computacional se ha realizado empleando el software Comsol Multiphysics 5.3a.

Adicionalmente, se ha realizado un análisis de sensibilidad de malla para las dos mallas de cálculo empleadas en el modelo (una correspondiente a la zona del lumen y otra a la zona de la pared arterial).

\section{Obtención de las geometrías}

Las geometrías calculadas se han obtenido a través de imágenes clínicas patológicas, es decir, con presencia de placa de ateroma (Ver Figura 1.A).
Dichas imágenes patológicas han sido procesadas con el software Mimics 20.0, para eliminar la placa de ateroma presente en ellas y obtener una geometría sana (Ver Figura 1.B), sin presencia de placa, en la cual, después de proceder a su extrusión para formar la pared arterial, se implementa el modelo computacional con el objetivo de comprobar si la placa obtenida mediante el modelo se sitúa en la misma zona que la presente en el paciente real.

\section{Modelo matemático}

El modelo matemático desarrollado emplea las ecuaciones de continuidad y de Navier-Stokes para el cálculo del flujo sanguíneo a lo largo del lumen. Adicionalmente, se emplea la Ley de Darcy para el cálculo de flujo de plasma que tiene lugar desde el lumen hacia la pared arterial.

Por otra parte, se calculan ecuaciones de conveccióndifusión-reacción para el cálculo de concentraciones de todas las sustancias que se han considerado en el modelo, y se han implementado las ecuaciones de Kedem-Katchalsky para el cálculo del flujo de sustancias a través del endotelio, el cual se realiza con el modelo de los tres poros [2]. Finalmente, el crecimiento de la placa se calcula mediante la siguiente ecuación [1]:

$$
\nabla \cdot v=\frac{\delta C_{F, w}}{\delta t} \cdot V_{F C}+\frac{\delta \Delta C_{S S, w}}{\delta t} \cdot V_{S S M C}+\frac{\delta C_{G, w}}{\delta t} \cdot \frac{1}{\rho_{G}}
$$

\section{Resultados}

Los resultados obtenidos muestran que en las zonas del modelo con bajo WSS (Ver Figura 2) hay un aumento de concentración de las sustancias que intervienen en el crecimiento de la placa de ateroma, como son las células musculares sintéticas, las células espumosas y las fibras de colágeno (Ver Figura 3). 
Finalmente, se ha comprobado que la placa de ateroma que se obtiene en la geometría sana mediante el modelo computacional, se aproxima de una forma bastante precisa a la placa presente en el paciente específico (Ver Figura 4).

\section{Conclusiones}

Se ha desarrollado un modelo computacional capaz de reproducir y, por tanto, prever, la formación de placa de ateroma en geometrías de paciente específico, en el cual el crecimiento de la placa está relacionado con la hemodinámica del flujo sanguíneo. Adicionalmente, se ha desarrollado un procedimiento de limpieza de imágenes clínicas patológicas, para obtener geometrías sanas y poder comprobar los resultados del modelo.

\section{FIGURAS / LEYENDAS}

A

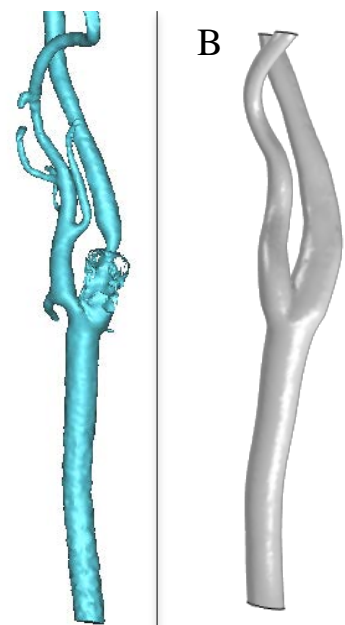

Fig. 1. Geometría de una de las carótidas. Izquierda: Geometría patológica (con placa); Derecha: Geometría limpia (sin placa)
Se está trabajando en la corrección de algunas limitaciones del presente modelo, como son la interacción fluido-estructura o el análisis de otras variables estímulo para la formación de placa (TAWSS, OSI y RT), pero el modelo puede ser ya considerado un paso importante en la compresión del proceso de formación de una placa de ateroma.

\section{REFERENCIAS}

[1]. M. Cilla, E. Peña, and M. A. Martínez. Mathematical modelling of atheroma plaque formation and development in coronary arteries. J. R. Soc. Interface 11:201308661, 2014

[2]. U. Olgac, V. Kurtcuoglu, and D. Poulikakos. Computational modeling of coupled blood-wall mass transport of LDL: effects of local wall shear stress. Am. J. Physiol. Heart Circ. Physiol. 294(2):909-919, 2008.

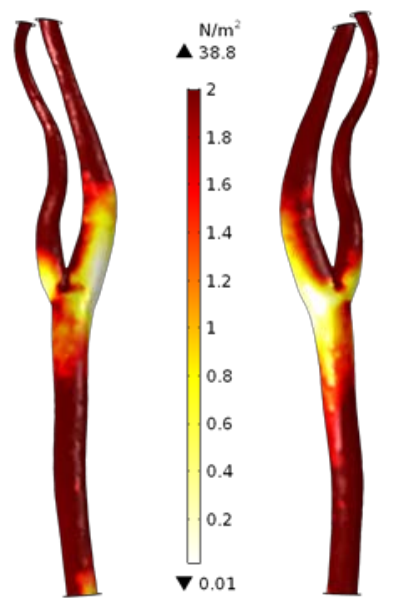

Fig. 2. Distribución de la tensión tangencial del flujo sanguíneo con la pared arterial. Filtrado con un límite máximo de $2 \mathrm{~Pa}$

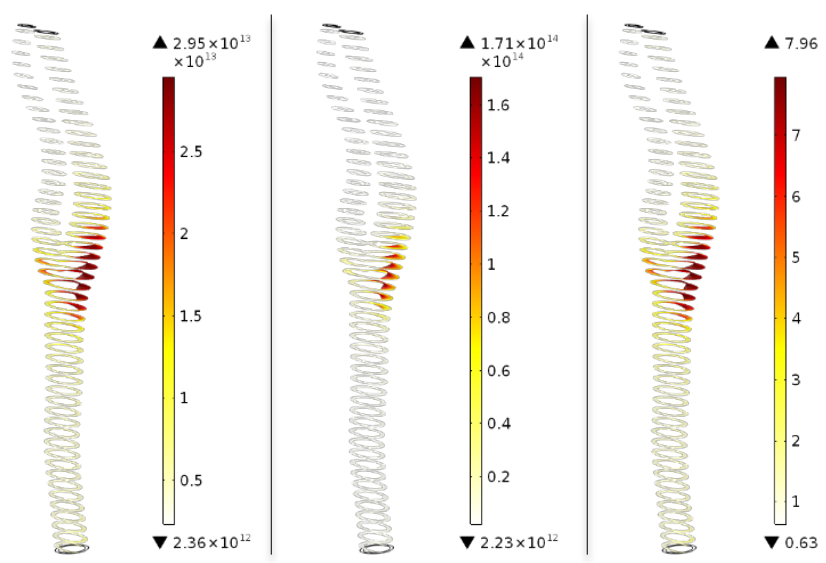

Fig. 3. Concentración en la pared arterial (representada en cortes a lo largo de toda la geometría de células musculares sintéticas (izquierda), células espumosas (centro) y fibras de colágeno (derecha). Concentración de células en células $/ \mathrm{m}^{3}$ y de colágeno en $\mathrm{g} / \mathrm{m}^{3}$

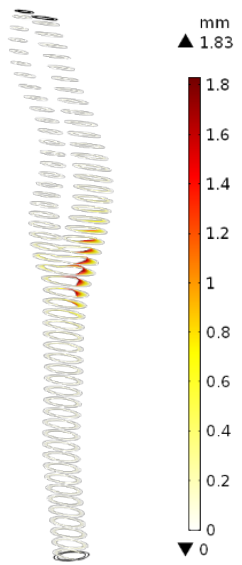

Fig. 4. Crecimiento de la placa de ateroma en la geometría limpia 